\title{
Behavior of tricellulin during destruction and formation of tight junctions under various extracellular calcium conditions
}

\author{
Akira Takasawa • Takashi Kojima • Takafumi Ninomiya • \\ Mitsuhiro Tsujiwaki • Masaki Murata $\cdot$ Satoshi Tanaka • \\ Norimasa Sawada
}

Received: 13 June 2012 / Accepted: 27 September 2012 / Published online: 17 October 2012

(C) The Author(s) 2012. This article is published with open access at Springerlink.com

\begin{abstract}
Tricellulin is an important component of tricellular tight junctions (TJs) and is involved in the formation of tricellular contacts. However, little is known about its regulation during the assembly and disassembly of tricellular TJs. By using the well-differentiated pancreatic cancer cell line HPAC, which highly expresses tricellulin at tricellular contacts, we have investigated changes in the localization, expression and phosphorylation of tricellulin and in its $\mathrm{TJ}$ functions as a barrier and fence during the destruction and formation of TJs induced by changes in the extracellular calcium concentration. During both extracellular $\mathrm{Ca}^{2+}$ depletion caused by EGTA treatment and $\mathrm{Ca}^{2+}$ repletion after $\mathrm{Ca}^{2+}$ starvation, the expression of tricellulin increased in whole lysates and in Triton-X-100-insoluble fractions without any change in its mRNA. The increases in immunoreactivity revealed by Western blotting were prevented by alkaline phosphatase treatment. Immunoprecipitation assays showed that tricellulin was phosphorylated on threonine residues when it increased after $\mathrm{Ca}^{2+}$ depletion and repletion.
\end{abstract}

Electronic supplementary material The online version of this article (doi:10.1007/s00441-012-1512-7) contains supplementary material, which is available to authorized users.

A. Takasawa $\cdot$ T. Kojima $\cdot$ M. Tsujiwaki $\cdot$ M. Murata $\cdot$ S. Tanaka $\cdot$

N. Sawada $(\bowtie)$

Department of Pathology,

Sapporo Medical University School of Medicine,

S1, W17,

Sapporo 060-8556, Japan

e-mail: sawadan@sapmed.ac.jp

T. Ninomiya

Department of Anatomy,

Sapporo Medical University School of Medicine,

Sapporo, Japan
In the early stage after $\mathrm{Ca}^{2+}$ repletion, tricellulin was expressed not only at tricellular contacts but also in the cytoplasm and at bicellular borders. In confocal laser microscopy, tricellulin was observed at the apical-most regions and basolateral membranes of tricellular contacts after $\mathrm{Ca}^{2+}$ repletion. Knockdown of tricellulin delayed the recovery of the barrier and fence functions after $\mathrm{Ca}^{2+}$ repletion. Thus, the dynamic behavior of tricellulin during the destruction and formation of TJs under various extracellular calcium conditions seems to be closely associated with the barrier and fence functions of TJs.

Keywords Tight junction - Tricellulin · Phosphorylation · Extracellular calcium $\cdot$ Barrier $\cdot$ Fence $\cdot$ Human pancreatic cancer cell line

\section{Introduction}

Tight junctions are the most apical components of intercellular junctional complexes. They inhibit solute and water flow through the paracellular space (termed the "barrier" function; Schneeberger and Lynch 1992; Gumbiner 1993). They also separate the apical from the basolateral cell surface domains, thereby establishing cell polarity (termed the "fence" function; van Meer and Simons 1986; Cereijido et al. 1998). The tight junction is formed not only by the integral membrane proteins such as the claudins, occludin and junctional adhesion molecules (JAMs) but also by many peripheral membrane proteins (Tsukita et al. 2001; Sawada et al. 2003; Schneeberger and Lynch 2004) that are regulated via distinct signal transduction pathways (González-Mariscal et al. 2008; Kojima et al. 2009). 
The tricellular tight junction forms at the convergence of bicellular tight junctions where three epithelial cells meet in polarized epithelia and is required for the maintenance of the transepithelial barrier (Ikenouchi et al. 2005). Recently, tricellulin has been identified as the third integral tight junction protein that predominantly localizes at tricellular tight junctions. Because of this, tricellulin has been characterized as the first marker of the tricellular tight junction in epithelial cells and its loss affects the organization of the tricellular tight junction and the barrier function of epithelial cells (Ikenouchi et al. 2005). Tricellulin is highly expressed in normal human pancreatic ducts and in well-differentiated ductal adenocarcinomas (Yamaguchi et al. 2010; Korompay et al. 2012). Furthermore, its mRNA expression has been detected in the human monocytic cell line THP-1 and in mature dendritic cells (Ogasawara et al. 2009). Similar to occludin and claudins, tricellulin contains four transmembrane domains with $\mathrm{N}$ - and $\mathrm{C}$ - terminal cytoplasmic tails, the C-terminal tail exhibiting homology to the occludin Cterminus. Both tricellulin and occludin contain the tetraspanning MARVEL (MAL and related proteins for vesicle trafficking and membrane link) domain that is present in proteins involved in membrane apposition and is concentrated in cholesterol-rich microdomains (Sánchez-Pulido et al. 2002). More recently, the lipolysis-stimulated lipoprotein receptor (LSR), originally identified and analyzed as a receptor for the uptake of triacylglyceride-rich lipoproteins (Yen et al. 1999), has been defined as an integral membrane protein localized at tricellular tight junctions and the cytoplasmic domain of LSR has been reported to be responsible for the recruitment of tricellulin (Masuda et al. 2011).

Knockdown or overexpression of occludin causes the mislocalization of tricellulin to bicellular tight junctions (Ikenouchi et al. 2008). Tricellulin is diminished by LSR knockdown, whereas LSR still accumulates at tricellular contacts after tricellulin knockdown (Masuda et al. 2011). The repression of tricellulin expression is related to Snailinduced epithelial mesenchymal transition in human gastric carcinoma (Masuda et al. 2010). We have recently reported that c-Jun N-terminal kinase (JNK) is involved in the regulation of tricellulin expression and prevents the disruption of the epithelial barrier in inflammation in human pancreatic duct epithelial cells (Kojima et al. 2010). However, little is known about the regulation of tricellulin during the assembly and disassembly of tight junctions.

The phosphorylation of tight junction proteins appears to play a central role in the regulation of tight junction assembly and function. In particular, multiple kinases targeting occludin and thereby modulating tight junction assembly, structure and function have been characterized and specific serine, threonine and tyrosine residues targeted by these kinases have been identified (Dörfel and Huber 2012).
Like occludin, tricellulin appears to be phosphorylated (Ikenouchi et al. 2005). However, the phosphorylation of tricellulin has not been studied in detail.

In this study of the polarized human pancreatic cancer cell line HPAC, in which tricellulin is highly induced at tricellular contacts, we have examined the behavior of tricellulin during the destruction and formation of tight junctions in response to changes in extracellular calcium concentrations. Dynamic changes in the distribution and phosphorylation of tricellulin have been observed during the destruction and formation of tight junctions.

\section{Materials and methods}

Antibodies, activators and inhibitors

Rabbit polyclonal anti-tricellulin (c-term), anti-occludin, anti-JAM-A, anti-claudin-1, anti-claudin-7 and antiphosphothreonine and mouse monoclonal anti-occludin (OC-3F10), anti-claudin-1 (2H10D10) and anti-claudin-4 (3E2C1) antibodies were obtained from Zymed Laboratories (San Francisco, Calif., USA). Rabbit polyclonal anti-actin and mouse monoclonal anti-E-cadherin antibodies were obtained from Sigma-Aldrich (St Louis, Mo., USA). Alexa 488 (green)-conjugated anti-rabbit IgG and Alexa 594 (red)conjugated anti-mouse IgG antibodies were purchased from Molecular Probes (Eugene, Ore., USA) and anti-rabbit IgG conjugated to 12-nm colloidal gold was purchased from Jackson ImmunoResearch Laboratories (Western Grove, Pa., USA).

\section{Culture of cell line and treatments}

Human pancreatic cancer cell line HPAC was purchased from the America Type Culture Collection (Manassas, Va., USA). HPAC cells were maintained with DMEM (SigmaAldrich) supplemented with $10 \%$ dialyzed fetal bovine serum (FBS; Invitrogen, Carlsbad, Calif., USA). The medium for the cell line contained $100 \mathrm{U} / \mathrm{ml}$ penicillin and $100 \mu \mathrm{g} /$ $\mathrm{ml}$ streptomycin and all cells were plated on 35- or $60-\mathrm{mm}$ culture dishes (Corning Glass Works, Corning, N.Y., USA) that were coated with rat tail collagen $(500 \mu \mathrm{g}$ dried tendon/ $\mathrm{ml}$ in $0.9 \%$ acetic acid) and incubated in a humidified $5 \%$ $\mathrm{CO}_{2}$ incubator at $37^{\circ} \mathrm{C}$.

Treatment with EGTA and $\mathrm{Ca}^{2+}$ repletion assay

For the $\mathrm{Ca}^{2+}$ depletion experiment, the HPAC cells were treated with a calcium chelator, namely $2.5 \mathrm{mM}$ EGTA, for $30 \mathrm{~min}$ and then cultured in medium without EGTA. For the calcium repletion assay, confluent HPAC cells were cultured in a low- $\mathrm{Ca}^{2+}$ medium $\left(20 \mu \mathrm{M} \mathrm{Ca}{ }^{2+}\right)$ with $1 \% \mathrm{FBS}$ 
overnight and then the medium was replaced by a normal medium containing $1.8 \mathrm{mM} \mathrm{Ca}^{2+}$.

\section{RNA interference and transfection}

For RNA interference studies, small interfering RNAs (siRNAs) duplex-targeting the mRNA sequences of human tricellulin were purchased from Invitrogen. A scrambled siRNA sequence (BLOCK-iT Alexa Fluor fluorescent, Invitrogen) was employed as control siRNA. At 1 day before transfection, the HPAC cells were plated in medium without antibiotics so that they would be half-confluent at the time of transfection. The cells were transfected with $100 \mathrm{nM}$ siRNAs by using Lipofectamine RNAiMAX (Invitrogen) as a carrier according to the manufacturer's instructions.

\section{Western blot analysis}

For Western blots of total cell lysates, the dishes were washed with phosphate-buffered saline (PBS) and $400 \mu \mathrm{l}$ sample buffer ( $1 \mathrm{mM} \mathrm{NaHCO} 3,2 \mathrm{mM}$ phenylmethylsulfonylfluoride) was added to the $60-\mathrm{mm}$ culture dishes. The cells were scraped off, collected in microcentrifuge tubes and then sonicated for $10 \mathrm{~s}$. The protein concentrations of samples were determined by using a BCA Protein Assay Reagent Kit (Pierce Chemical, Rockford, Ill., USA). Aliquots of $15 \mu \mathrm{g}$ protein/lane for each sample were separated by electrophoresis in $4 \% / 20 \%$ SDS polyacrylamide gels (Cosmo Bio, Tokyo, Japan). After electrophoretic transfer to nitrocellulose membranes (Immobilon; Millipore, Billerica, Mass., USA), the membranes were saturated with blocking buffer (Tris-buffered saline [TBS] with $0.1 \%$ Tween 20, 4\% skim milk) for $30 \mathrm{~min}$ at room temperature and incubated with anti-tricellulin, anti-occludin, anti-claudin1, anti-claudin-4, anti-claudin-7, anti-phosphothreonine, or anti-actin antibodies (1:1000) for $1 \mathrm{~h}$ at room temperature. The membranes were incubated with horseradish-peroxidaseconjugated anti-rabbit or mouse IgG (Dako, Copenhagen, Denmark) at room temperature for $1 \mathrm{~h}$. Immunoreactive bands were detected by using an ECL Western blotting analysis system (GE Healthcare, Little Chalfont, UK).

Triton-X-100-soluble and -insoluble fractions

The dishes were washed with PBS twice, lysed in Triton X100 buffer (1\% Triton X-100, $100 \mathrm{mM} \mathrm{NaCl}, 10 \mathrm{mM}$ HEPES, pH 7.6, 2 mM EDTA, $1 \mathrm{mM}$ phenylmethane sulfonyl fluoride [PMSF], $4 \mathrm{mM}$ sodium orthovanadate, $40 \mathrm{mM}$ sodium fluoride). The lysates were centrifuged at $15,000 \mathrm{~g}$ for $20 \mathrm{~min}$ at $4^{\circ} \mathrm{C}$. The soluble supernatant was collected and this fraction was defined as the Triton-X-100soluble fraction. The pellet was solubilized in Triton X-100 buffer containing 1\% SDS by using an ultrasonic disintegrator and cleared by centrifugation at $15,000 \mathrm{~g}$ for $5 \mathrm{~min}$ at $4^{\circ} \mathrm{C}$; this fraction was defined as the Triton-X-100-insoluble fraction. After the protein concentration of each sample had been quantified by using a BCA protein assay reagent kit (Pierce Chemical), the fractions were subjected to Western blot analysis with anti-tricellulin and anti-actin antibodies.

\section{Alkaline phosphatase treatment}

Whole cell lysates and the Triton-X-100-insoluble fraction were incubated with $20 \mathrm{U}$ calf intestine alkaline phosphatase (Takara Shuzo, Ohtsu, Japan) for $1 \mathrm{~h}$ at $37^{\circ} \mathrm{C}$ with occasional mixing and then subjected to Western blot analysis with anti-tricellulin and anti-actin antibodies.

Immunoprecipitation

The dishes were washed with PBS twice and $300 \mu 1$ NP-40 lysis buffer $(50 \mathrm{mM}$ Tris- $\mathrm{HCl}, 2 \% \mathrm{NP}-40,0.25 \mathrm{mM} \mathrm{Na}-$ deoxycholate, $150 \mathrm{mM} \mathrm{NaCl}, 2 \mathrm{mM}$ EGTA, $0.1 \mathrm{mM}$ $\mathrm{Na}_{3} \mathrm{VO}_{4}, 10 \mathrm{mM} \mathrm{NaF}, 2 \mathrm{mM}$ PMSF) was added to the $60-$ $\mathrm{mm}$ dishes. The cells were scraped off, collected in microcentrifuge tubes and then sonicated for $10 \mathrm{~s}$. Cell lysates were incubated with protein A-Sepharose CL-4B (Pharmacia LKB Biotechnology, Uppsala, Sweden) for $1 \mathrm{~h}$ at $4^{\circ} \mathrm{C}$ and then clarified by centrifugation at $15,000 \mathrm{~g}$ for $10 \mathrm{~min}$. The supernatants were incubated with the polyclonal anti-tricellulin antibody bound to protein A-Sepharose CL-4B overnight at $4{ }^{\circ} \mathrm{C}$. After incubation, immunoprecipitates were washed extensively with the same lysis buffer and subjected to Western blot analysis with anti-tricellulin and anti-phosphothreonine antibodies.

RNA isolation, reverse transcription polymerase chain reaction analysis and real-time polymerase chain reaction analysis

Total RNA was extracted and purified by using TRIzol (Invitrogen); $1 \mu \mathrm{g}$ total RNA was reverse-transcribed into cDNA by using a mixture of oligo (dT) and Superscript II reverse transcriptase according to the manufacturer's recommendations (Invitrogen). Synthesis of each cDNA was performed in a total volume of $20 \mu \mathrm{l}$ for $50 \mathrm{~min}$ at $42^{\circ} \mathrm{C}$ and terminated by incubation for $15 \mathrm{~min}$ at $70^{\circ} \mathrm{C}$. The polymerase chain reaction (PCR) was performed in a $20-\mu$ l total mixture containing $10 \mathrm{pmol}$ primer pairs, $1.0 \mu \mathrm{l}$ of the $20-\mu \mathrm{l}$ total reverse transcription (RT) product, PCR buffer, dNTPs and Taq DNA polymerase according to the manufacturer's recommendations (Takara, Kyoto, Japan). Amplifications were carried out for 25-35 cycles depending on the PCR primer pair with cycle times of $15 \mathrm{~s}$ at $96^{\circ} \mathrm{C}, 30 \mathrm{~s}$ at $55^{\circ} \mathrm{C}$ and $60 \mathrm{~s}$ at $72^{\circ} \mathrm{C}$. The final elongation time was $7 \mathrm{~min}$ 
at $72^{\circ} \mathrm{C}$. Of the total $20-\mu \mathrm{l}$ PCR product, $7 \mu \mathrm{l}$ was analyzed by $1 \%$ agarose gel electrophoresis with ethidium bromide staining and standardized by using a GeneRuler 100-bp DNA ladder (Fermentas, Ontario, Canada).

Real-time PCR detection was performed by using a TaqMan Gene Expression Assay kit with a StepOnePlus real-time PCR system (Applied Biosystems, Foster City, Calif., USA). The amount of $18 \mathrm{~S}$ ribosomal RNA (Hs99999901) in each sample was used to standardize the quantity of the mRNA of tricellulin (Hs00930631). The relative mRNA expression levels between the control and treated samples were calculated by the difference of the threshold cycle (comparative $\mathrm{C}_{\mathrm{T}}\left[\Delta \mathrm{C}_{\mathrm{T}}\right]$ method) and presented as the average of triplicate experiments with a $95 \%$ confidence interval.

\section{Immunostaining}

The cells were grown on 35-mm glass-base dishes (Iwaki, Chiba, Japan) coated with rat tail collagen and incubated with 10\% FBS. They were then fixed with cold acetone and ethanol $(1: 1)$ at $-20^{\circ} \mathrm{C}$ for $10 \mathrm{~min}$. After being rinsed in PBS, they were incubated with polyclonal anti-tricellulin or monoclonal anti-occludin $(1: 100)$ at room temperature for $1 \mathrm{~h}$ and then with Alexa 488 (green)-conjugated anti-rabbit IgG and Alexa 594 (red)-conjugated anti-mouse IgG antibodies $(1: 200)$ at room temperature for $1 \mathrm{~h}$. Some cells were double-stained by using polyclonal anti-tricellulin and monoclonal anti-occludin and were visualized with Alexa 488 (green)-conjugated anti-rabbit IgG and Alexa 594 (red)conjugated anti-mouse IgG antibodies. Cell nuclei were counterstained with 4,6-diamidino-2-phenylindole (DAPI; Sigma-Aldrich). The specimens were examined by using an epifluorescence microscope (Olympus, Tokyo, Japan) and a confocal laser scanning microscope (LSM510; Carl Zeiss, Jena, Germany).

Immuno-transmission electron microscopic analysis

HPAC cells grown to confluence on $60-\mathrm{mm}$ tissue culture dishes were scraped from the dishes and collected in microcentrifuge tubes for immuno-transmission electron microscopic (immuno-TEM) analysis. After fixation with 4\% paraformaldehyde and $0.1 \%$ glutaraldehyde in PBS for $20 \mathrm{~min}$, the cells were incubated with 5\% normal donkey serum in PBS for $15 \mathrm{~min}$ at room temperature to block nonspecific reactions. Then, they were incubated with the anti-tricellulin antibody $(1: 100)$ overnight at $4{ }^{\circ} \mathrm{C}$. After incubation, the cells were washed five times with PBS with Triton X-100 for 5 min each time and incubated with 12-nm colloidal-gold-conjugated anti-rabbit $\operatorname{IgG}(1: 50)$. After five washes with PBS for 5 min each time, the specimens were fixed with $1.0 \%$ glutaraldehyde in PBS for $60 \mathrm{~min}$ at $4^{\circ} \mathrm{C}$.
The specimens were then rinsed with distilled water and incubated with $0.05 \mathrm{M}$ HEPES solution for $30 \mathrm{~min}$ at room temperature. Following incubation, they were enhanced with a silver enhancement kit (Jackson Immuno Research Laboratories). The specimens were rinsed with distilled water, fixed with $2.5 \%$ glutaraldehyde in PBS for 90 min at room temperature, dehydrated through a graded ethanol series, embedded in epoxy resin and cut into ultrathin sections with a Sorvall MT6000 ultramicrotome (DEDUPOMT, New Castle, Del., USA). The ultrathin sections were stained with uranyl acetate and lead citrate and examined with a transmission electron microscope (H7500; Hitachi, Tokyo, Japan).

Measurement of transepithelial electrical resistance

The cells were cultured to confluence on the inner chambers of 12-mm Transwells with $0.4-\mu \mathrm{m}$ pore-size filters (Corning Life Science). Transepithelial electrical resistance (TER) was measured by using an EVOM voltmeter with an ENDOHM-12 (World Precision Instruments, Sarasota, Fla., USA) on a heating plate (Fine, Tokyo, Japan) adjusted to $37^{\circ} \mathrm{C}$. The values are expressed in standard units of ohms per square centimeter and presented as means $\pm \mathrm{SD}$ of triplicate experiments. For calculation, the resistance of blank filters was subtracted from that of filters covered with cells.

\section{Diffusion of BODIPY-sphingomyelin}

For measurement of the tight-junctional fence function, we used the diffusion of BODIPY-sphingomyelin (Balda et al. 1996) with some modification (Kojima et al. 2008). Sphingomyelin/bovine serum albumin (BSA) complexes $(5 \mathrm{nM})$ were prepared in P buffer (10 nM HEPES, $\mathrm{pH}$ 7.4, $1 \mathrm{mM}$ sodium pyruvate, $10 \mathrm{mM}$ glucose, $3 \mathrm{mM} \mathrm{CaCl}_{2}$, $145 \mathrm{mM} \mathrm{NaCl}$ ) by using BODIPY-FL-sphingomyelin (Molecular Probes) and defatted BSA. Cells plated on glass-bottom microwell plates (Mat Tek, Ashland, Mass., USA) were loaded with the BODIPY-sphingomyelin/BSA complex for $1 \mathrm{~min}$ on ice, after which they were rinsed with cold DMEM and mounted in DMEM on a glass slide. The samples were analyzed by confocal laser scanning microscopy (LSM510; Carl Zeiss).

\section{Data analysis}

Signals were quantified by using Scion Image Beta 4.02 Win (Scion, Frederick, Mass., USA). Each set of results shown is representative of at least three separate experiments. Results are given as means \pm SE. Differences between groups were tested by analysis of variance followed by a post hoc test and an unpaired two-tailed Student's $t$-test and considered to be significant when $P<0.05$. 


\section{Results}

Effects of intracellular $\mathrm{Ca}^{2+}$ on expression and localization of tricellulin in HPAC cells

Tricellulin was expressed at tricellular contacts in differentiated human pancreatic duct carcinoma cell line HPAC as we previously reported (Fig. 1a; Kojima et al. 2010). To investigate the effects of intracellular $\mathrm{Ca}^{2+}$ on the expression and localization of tricellulin in HPAC cells, the cells were treated with a calcium chelator, namely $2.5 \mathrm{mM}$ EGTA.

When the membranes of tricellular contacts began to detach, gaps formed at these regions from $5 \mathrm{~min}$ after EGTA treatment but tricellulin was initially maintained at the membranes around the gap formation (Fig. 1b). At $30 \mathrm{~min}$ after treatment, tricellulin was not detected at the membranes and was observed in the cytoplasm (Fig. 1d). Occludin remained in membranes for 30 min during EGTA treatment. In Western blots of whole lysates, tricellulin was increased from $5 \mathrm{~min}$ after EGTA treatment and was significantly upregulated 2.6-fold and 4.3-fold compared with the control level at 15 and $30 \mathrm{~min}$ after treatment with EGTA, respectively, whereas occludin and claudin-1, -4 and -7 were unchanged (Fig. 1e, f). Triton-X-100-soluble and -insoluble fractions are operational definitions that have been used to define the localization of tight junction proteins biochemically (Nusrat et al. 2000). Because tricellulin was invariably found to be Triton-X-100-insoluble, only Triton-X-100-insoluble fractions were analyzed. Under the same exposure time as for Western blotting, the amount of tricellulin in the Triton-X-100-soluble fraction was small compared with that in the Triton X-100-insoluble fraction (Supplemental
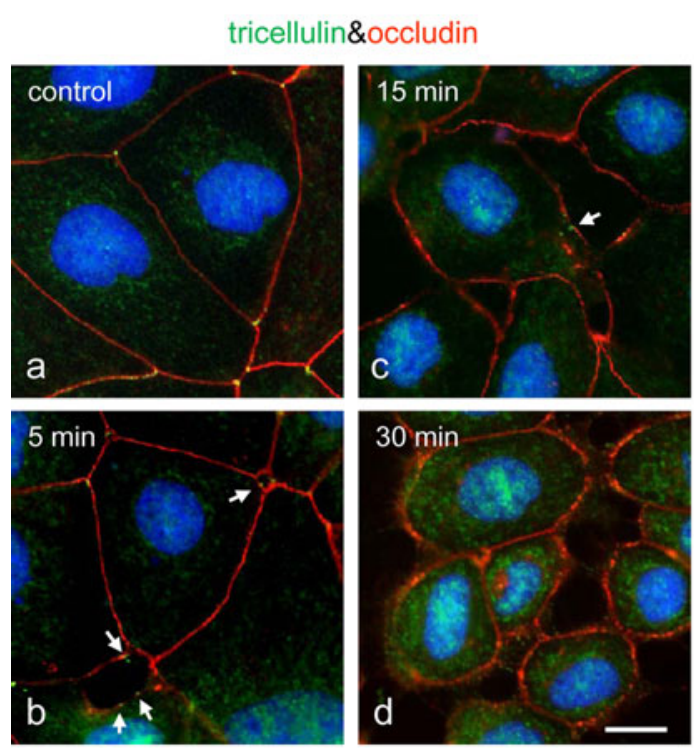

e
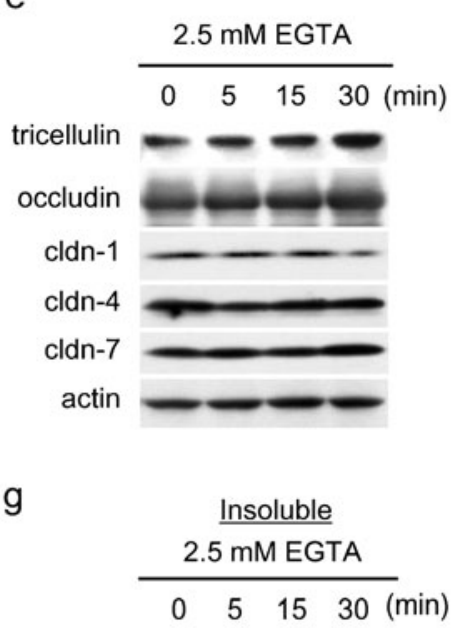

tricellulin

actin

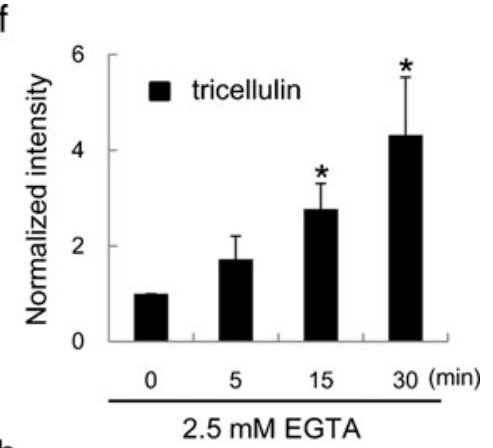

$\mathrm{h}$
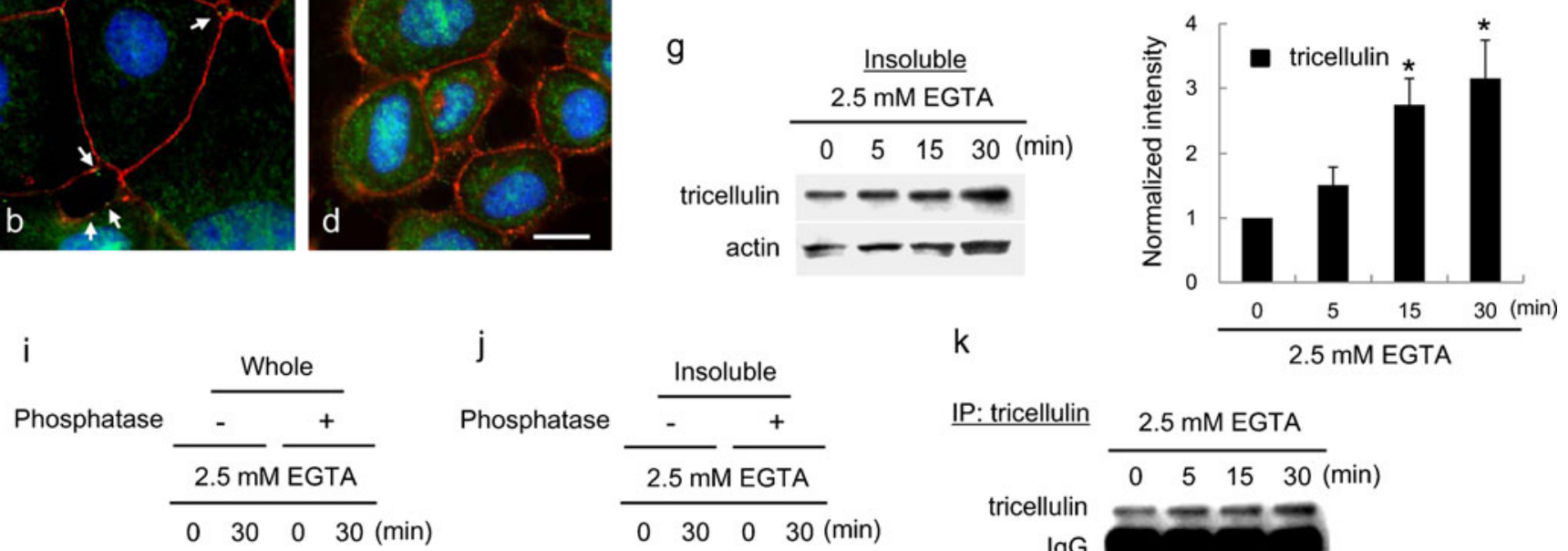

j
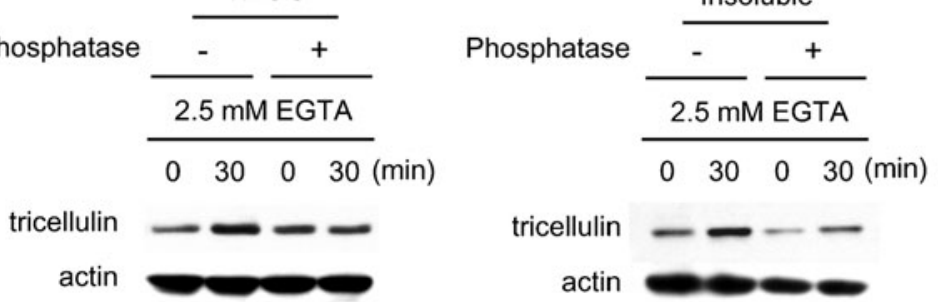

k

p-threonine

$\lg G$

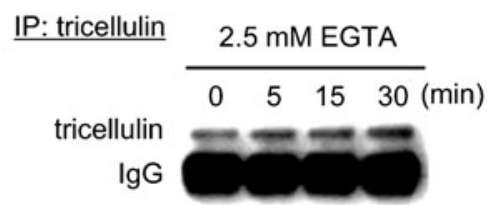

Fig. 1 Expression and distribution of tricellulin in the human pancreatic cancer cell line (HPAC) after treatment with EGTA. a-d Immunostaining images obtained by using double-staining for tricellulin (green) and occludin (red) in HPAC cells after treatment with $2.5 \mathrm{mM}$ EGTA (arrows gaps). Nuclei are shown in blue (DAPI staining) Bar $20 \mu \mathrm{m}$. e Western blotting for tricellulin, occludin, claudin $(c l d n)-1,-4$ and -7 and actin in whole cell lysates of HPAC cells after treatment with $2.5 \mathrm{mM}$ EGTA. Expression levels of tricellulin are shown in $\mathbf{f}$ in a bar graph $\left(n=4,{ }^{*} P<0.05\right.$ versus $\left.0 \mathrm{~h}\right)$. $\mathbf{g}$ Western blotting for tricellulin in the Triton-X-100-insoluble fraction (Insoluble) of HPAC cells after treatment with $2.5 \mathrm{mM}$ EGTA. Expression levels of tricellulin are shown in $\mathbf{h}$ in a bar graph $\left(n=4,{ }^{*} P<0.05\right.$ versus $\left.0 \mathrm{~h}\right) . \mathbf{i}, \mathbf{j}$ Western blotting for tricellulin in whole cell lysates (Whole) and in the Triton-X-100-insoluble fraction (Insoluble). After 2.5 mM EGTA treatment, HPAC cells were lysed and then treated with or without alkaline phosphatase, followed by detergent extraction. $\mathbf{k}$ Western blotting for phosphothreonine in immunoprecipitates $(I P)$ by using an anti-tricellulin antibody in HPAC cells after treatment with 2.5 mM EGTA 
Fig. 2). From 5 min after treatment with $2.5 \mathrm{mM}$ EGTA, tricellulin increased in the Triton-X-100-insoluble fractions (Fig. 1g, h). Treatment of whole cell lysates with alkaline phosphatase prevented the upregulation of tricellulin in whole lysates and Triton-X-100-insoluble fractions at $30 \mathrm{~min}$ after treatment with EGTA (Fig. 1i, j).

In immunoprecipitates examined by using the antitricellulin antibody, phosphothreonine was detected and increased from 5 min after EGTA treatment (Fig. 1k).

In RT-PCR and real-time RT-PCR, no changes of mRNAs of tricellulin, occludin and claudin-1, -4 , and -7 were observed after EGTA treatment (Supplemental Fig. 1a, b).

After treatment with $2.5 \mathrm{mM}$ EGTA for $30 \mathrm{~min}$, the cells were transferred to normal medium without EGTA. As shown in Fig. 2a, TER values indicated that the tight junction barrier gradually decreased until $30 \mathrm{~min}$ after EGTA treatment and then promptly recovered to normal levels after 120 min without EGTA treatment (Fig. 2a). The upregulation of tricellulin at $30 \mathrm{~min}$ after EGTA treatment in Western blots was completely inhibited after $60 \mathrm{~min}$ without EGTA treatment (Fig. 2b). In immunostaining, tricellulin, which had disappeared from the membranes at $30 \mathrm{~min}$ after EGTA treatment, was recruited into the membranes of tricellular contacts after 60 min without EGTA treatment (Fig. 2c-k).
After 60 min without EGTA treatment (Fig. 2, R60 min), the localization of tricellulin showed heterogeneity. Tricellulin was observed at various positions including not only tricellular tight junctions but also bicellular tight junctions and cytoplasm.

Changes of expression of tricellulin during $\mathrm{Ca}^{2+}$ repletion in HPAC cells

As shown in Fig. 2c-k, removal of EGTA resulted in a heterogeneous localization of tricellulin. Most tricellulin was immediately localized at tricellular tight junctions but some was still in the cytoplasm. Therefore, we decided to examine the behavior of tricellulin during the formation of tight junctions under various experimental conditions. To achieve homogeneous culture with $\mathrm{Ca}^{2+}$ starvation, HPAC cells were cultured in a low $-\mathrm{Ca}^{2+}$ medium (containing $20 \mu \mathrm{M} \mathrm{Ca}^{2+}$ ) overnight under confluent conditions. These $\mathrm{Ca}^{2+}$-starved cultures were transferred to normal $\mathrm{Ca}^{2+}$ medium $\left(1.8 \mathrm{mM} \mathrm{Ca}^{2+}\right)$ and the behavior of tricellulin during the formation of tight junctions was investigated.

As shown in Fig. 3a, the TER value rapidly increased on $\mathrm{Ca}^{2+}$ repletion in a time-dependent manner and reached a plateau at $4 \mathrm{~h}$ after $\mathrm{Ca}^{2+}$ repletion. In Western blots of whole a

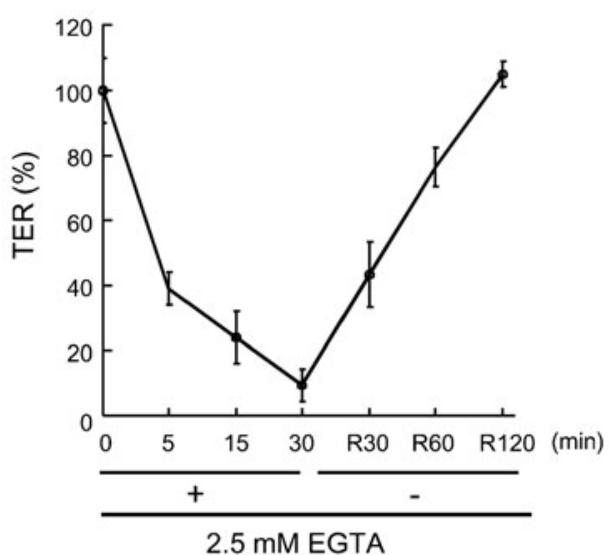

b

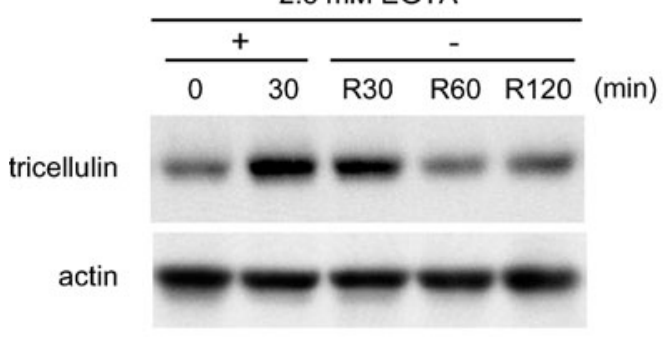

control
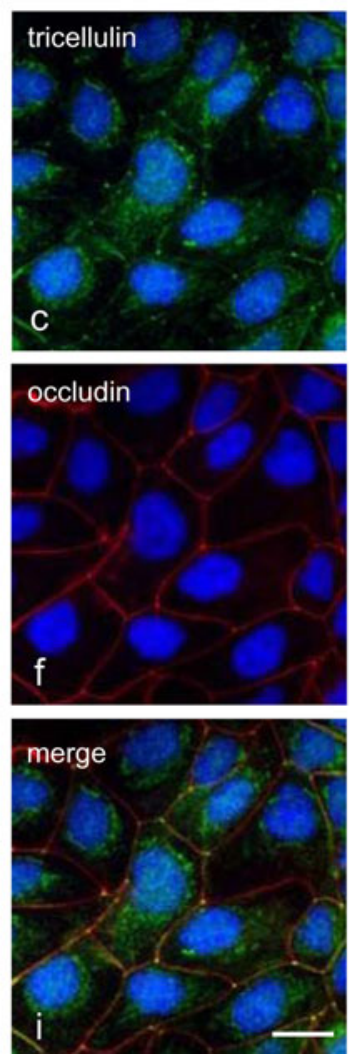

$30 \mathrm{~min}$
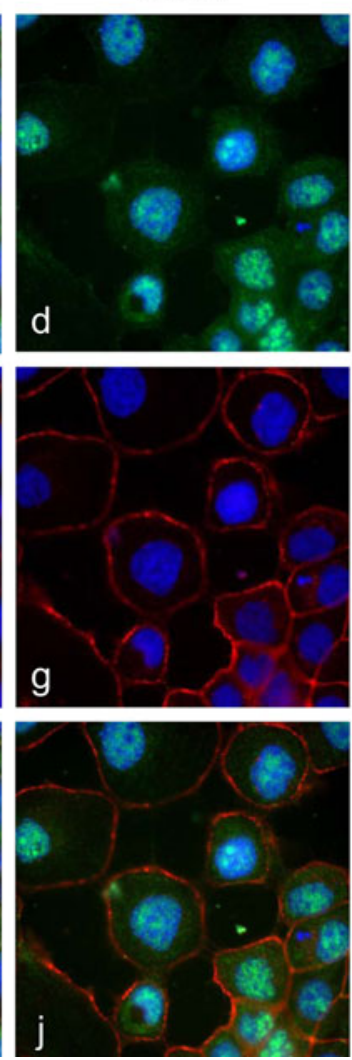

$\mathrm{R} 60$ min
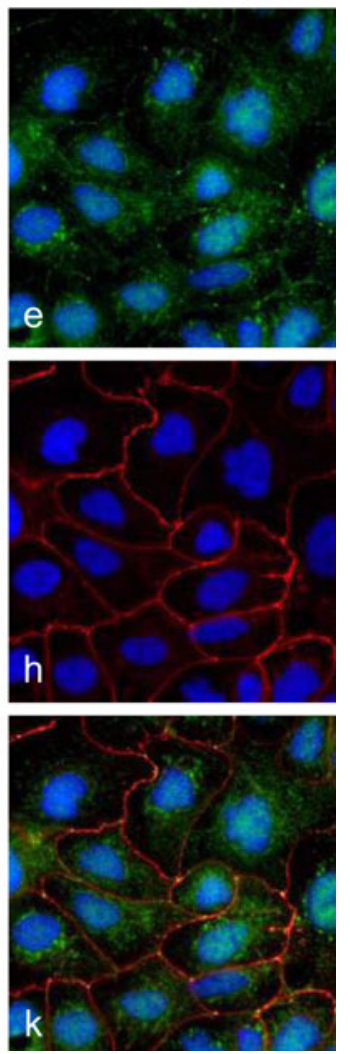

Fig. 2 a Transepithelial electrical resistance (TER) values. b Western blotting for tricellulin. $\mathbf{c}-\mathbf{k}$ Immunostaining of tricellulin and occludin in HPAC cells. After treatment with $2.5 \mathrm{mM}$ EGTA for $30 \mathrm{~min}$, HPAC cells were transferred to normal medium without EGTA ( $R$ recovery). Bar $20 \mu \mathrm{m}$ 


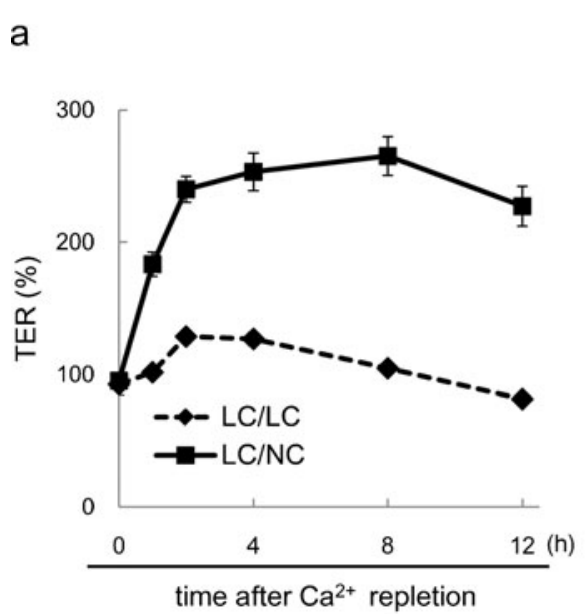

d

b

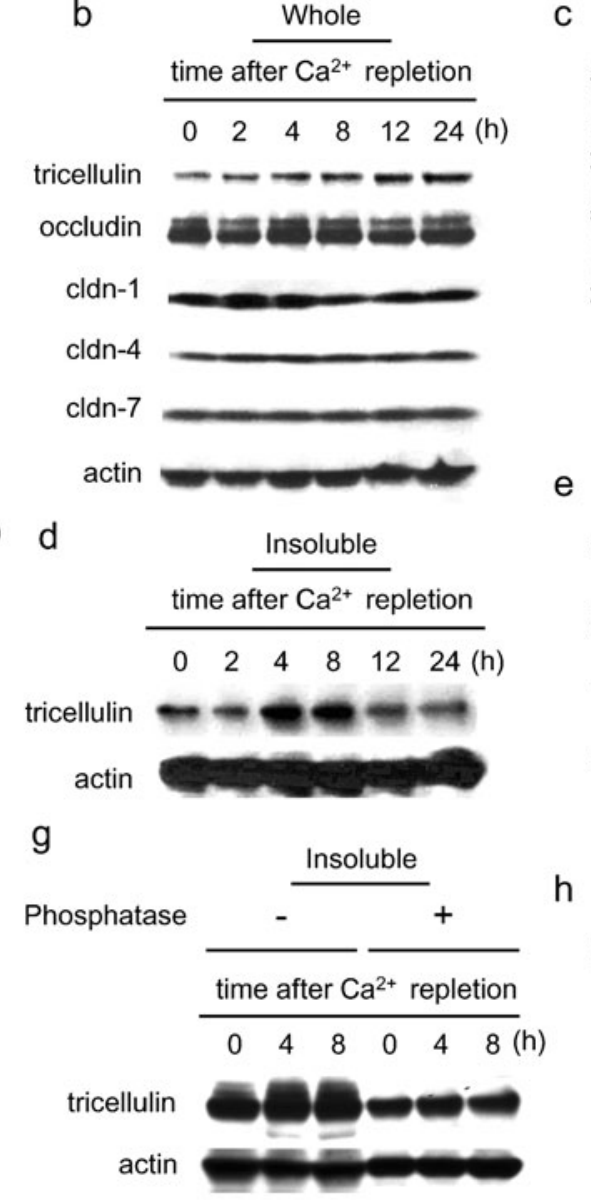

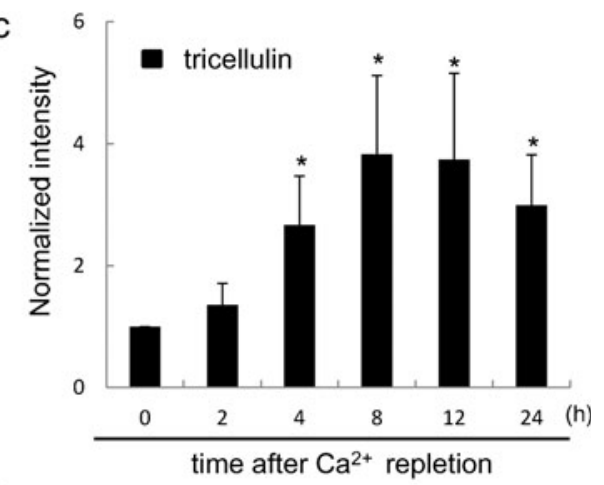
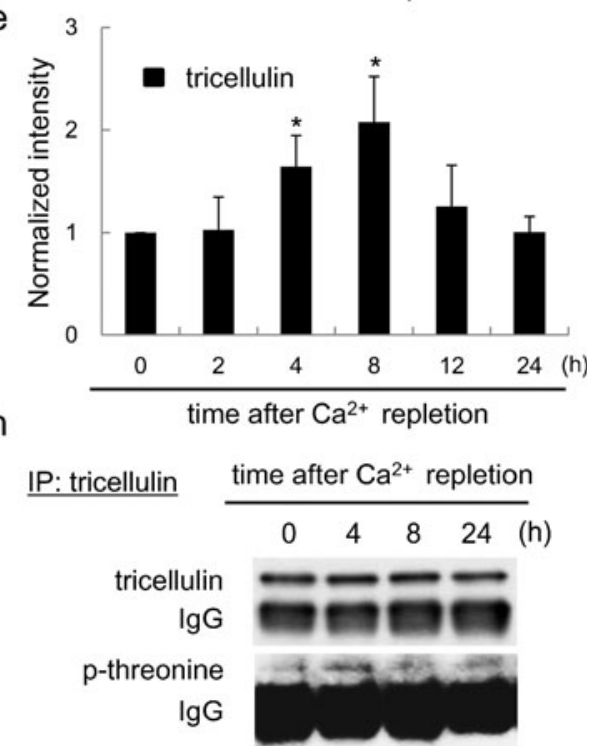

Fig. 3 Changes of expression of tricellulin and barrier function during the $\mathrm{Ca}^{2+}$ repletion in HPAC cells. a TER values in HPAC cells during the $\mathrm{Ca}^{2+}$ repletion. HPAC cells were cultured in a low- $\mathrm{Ca}^{2+}$ medium $\left(20 \mu \mathrm{M} \mathrm{Ca}{ }^{2+} ; L C\right)$ overnight and then transferred to normal $\mathrm{Ca}^{2+}$ medium $(L C / N C)$ or to fresh low-Ca ${ }^{2+}$ medium $(L C / L C)$. b Western blotting for tricellulin, occludin and claudin (cldn) $-1,-4$ and -7 in whole cell lysates of HPAC cells (Whole) after $\mathrm{Ca}^{2+}$ repletion. Expression levels of tricellulin are shown in $\mathbf{c}$ in a bar graph $(n=4, * P<0.05$ versus $0 \mathrm{~h}$ ). d Western blotting for tricellulin in the Triton-X-100-

lysates, tricellulin increased from $2 \mathrm{~h}$ after $\mathrm{Ca}^{2+}$ repletion and was significantly upregulated from $4 \mathrm{~h}$ until $24 \mathrm{~h}$, with a maximal level at $8 \mathrm{~h}(1.31$-fold at $2 \mathrm{~h} ; 2.71$-fold at $4 \mathrm{~h} ; 3.62$ fold at $8 \mathrm{~h} ; 3.47$-fold at $12 \mathrm{~h} ; 2.89$-fold at $24 \mathrm{~h}$ ), whereas no changes of occludin or claudin-1, -4 and -7 were observed (Fig. 3b, c). As shown in Fig. 3d, e, tricellulin in Triton-X100 -insoluble fractions reached a maximal level from $4 \mathrm{~h}$ to $8 \mathrm{~h}$ after $\mathrm{Ca}^{2+}$ repletion and then declined to the control level at $24 \mathrm{~h}$. Under the same exposure time as for Western blotting, the amount of tricellulin in the Triton-X-100-soluble fraction was small compared with that in the Triton-X-100insoluble fraction, as described above for EGTA treatment (Supplemental Fig. 3). Treatment with alkaline phosphatase prevented the upregulation of tricellulin in whole lysates and Triton-X-100-insoluble fractions from $4 \mathrm{~h}$ to $8 \mathrm{~h}$ after $\mathrm{Ca}^{2+}$ repletion (Fig. 3f, g). Notably, in Triton-X-100-insoluble insoluble fraction (Insoluble) of HPAC cells after $\mathrm{Ca}^{2+}$ repletion. Expression levels of tricellulin are shown in $\mathbf{e}$ in a bar graph $(n=3$, $* P<0.05$ versus $0 \mathrm{~h}$ ). $\mathbf{f}, \mathbf{g}$ Western blotting for tricellulin in whole cell lysates (Whole) and in the Triton-X-100-insoluble fraction (Insoluble) of HPAC cells with or without alkaline phosphatase up until $8 \mathrm{~h}$ after $\mathrm{Ca}^{2+}$ repletion. h Western blotting for phosphothreonine after immunoprecipitation $(I P)$ by using an anti-tricellulin antibody in HPAC cells after $\mathrm{Ca}^{2+}$ repletion

fractions, an increasing width caused by an upward band shift became evident after $4 \mathrm{~h}$ and treatment with alkaline phosphatase significantly decreased the apparent molecular mass of the tricellulin band. In immunoprecipitation assays with the anti-tricellulin antibody, phosphothreonine was maximally increased at $4 \mathrm{~h}$ after $\mathrm{Ca}^{2+}$ repletion (Fig. 3h).

In RT-PCR and real-time PCR, no changes of mRNAs of tricellulin, occludin, or claudin-1, -4 and -7 were observed during $\mathrm{Ca}^{2+}$ repletion (Supplemental Fig. 1c, d).

Changes of localization of tricellulin during $\mathrm{Ca}^{2+}$ repletion in HPAC cells

The localization of tricellulin during the formation of tight junctions over the course of $\mathrm{Ca}^{2+}$ repletion was examined by immunostaining and immuno-TEM analysis. During 
low- $\mathrm{Ca}^{2+}$ treatment, no tricellulin was detected in any cytoplasmic membranes (Fig. 4). At $4 \mathrm{~h}$ after $\mathrm{Ca}^{2+}$ repletion, tricellulin immunoreactivity was observed not only at tricellular contacts but also in the cytoplasm and at bicellular borders. By $8 \mathrm{~h}$ after $\mathrm{Ca}^{2+}$ repletion, tricellulin immunoreactivity had decreased in the cytoplasm and at bicellular borders but was strongly detected at tricellular contacts. At $24 \mathrm{~h}$ after $\mathrm{Ca}^{2+}$ repletion, tricellulin was recruited to the membranes of tricellular contacts. In Z-sections obtained by confocal laser microscopy, tricellulin was observed not only at the apicalmost regions but also at basolateral membranes at $4 \mathrm{~h}$ after $\mathrm{Ca}^{2+}$ repletion, whereas in control cells, it was observed at the apical-most regions of tricellular contacts (Fig. 5a, b).

In the control, some immunogold particles directed against tricellulin were observed on the membranes around the closed tricellular contact by immuno-TEM analysis (Fig. 5c). At $4 \mathrm{~h}$ after $\mathrm{Ca}^{2+}$ repletion, the immunogold particles were observed along the membranes, around small spaces and at bicellular borders (Fig. 5d).

Effects on barrier and fence functions during $\mathrm{Ca}^{2+}$ repletion by knockdown of tricellulin in HPAC cells

To investigate whether knockdown of tricellulin by siRNAs affected the barrier and fence functions of tight junctions during $\mathrm{Ca}^{2+}$ repletion, we examined TER for barrier function assays and performed diffusion assays with BODIPYsphingomyelin for fence function assay.

At $48 \mathrm{~h}$ after transfection with two sets of $100 \mathrm{nM}$ siRNAs for tricellulin, tricellulin was decreased compared with the control in Western blots, whereas no changes in occludin or claudin-1, -4 and -7 were observed (Fig. 6a). At $48 \mathrm{~h}$ after transfection with $100 \mathrm{nM}$ siRNA-1 for tricellulin, tricellulin-positive spots disappeared at the tricellular contacts, whereas occludin was expressed at the cell borders as in the control (Fig. 6b-g). In RT-PCR, tricellulin mRNA decreased compared with the control, whereas no changes of occludin or claudin-1, -4 and -7 were observed (Supplemental Fig. 1e).

The increase of TER values until $4 \mathrm{~h}$ after $\mathrm{Ca}^{2+}$ repletion was inhibited by the two sets of $100 \mathrm{nM}$ siRNAs for tricellulin compared with the control (Fig. 6h). BODIPYsphingomyelin was effectively retained at the apical domain of control cells. At $0 \mathrm{~h}$ after $\mathrm{Ca}^{2+}$ repletion, the BODIPYsphingomyelin diffused through the tight junctions, being strongly labeled at the basolateral and basal surfaces and appearing to penetrate the cells, indicating that the fence function of tight junctions was reduced. At $4 \mathrm{~h}$ after $\mathrm{Ca}^{2+}$ repletion, diffusion of the probe was markedly decreased compared with that of $0 \mathrm{~h}$. The probe was effectively retained in the apical domain at $8 \mathrm{~h}$ after $\mathrm{Ca}^{2+}$ repletion. In cells transfected with $100 \mathrm{nM}$ siRNA-1 for tricellulin, diffusion of the probe was in part observed at the basolateral surfaces at $4 \mathrm{~h}$ and $8 \mathrm{~h}$ after $\mathrm{Ca}^{2+}$ repletion.

\section{Discussion}

To elucidate the roles of tricellulin in the establishment of tight junctions, we examined the behavior of endogenous time after $\mathrm{Ca}^{2+}$ repletion

Fig. 4 a-l Immunostaining images obtained by using double-staining for tricellulin and occludin in HPAC cells after $\mathrm{Ca}^{2+}$ repletion. Bar $20 \mu \mathrm{m}$
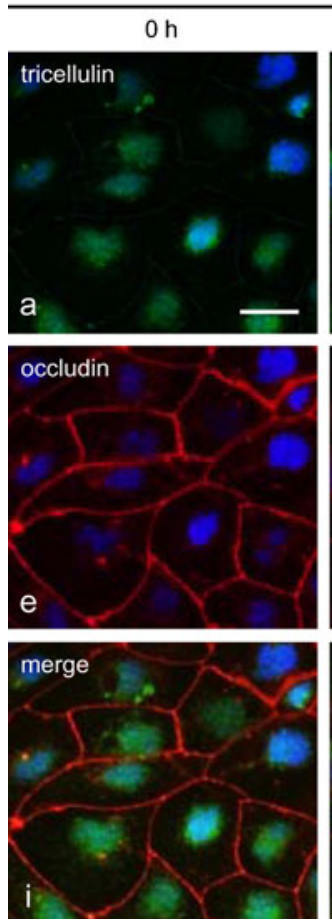
$8 \mathrm{~h}$
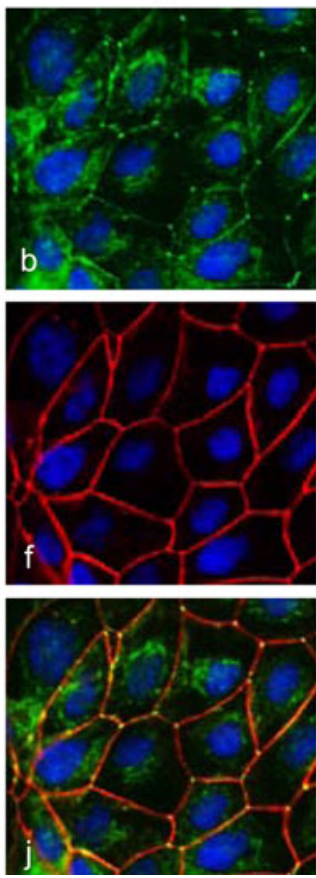
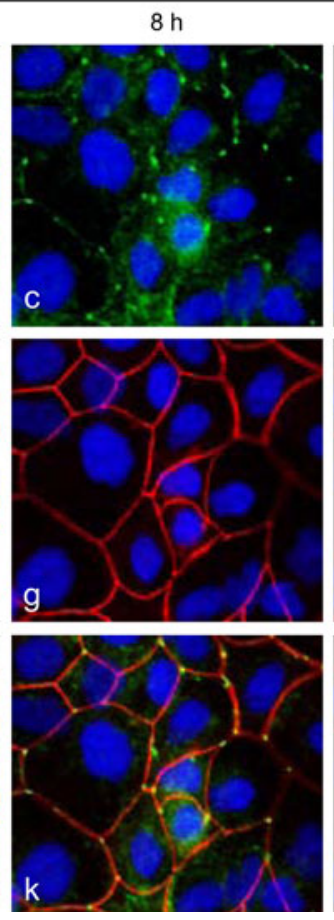
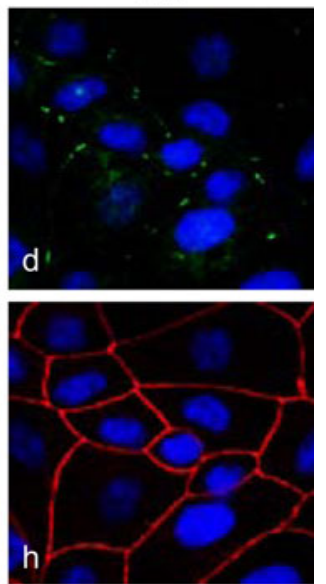

$24 \mathrm{~h}$

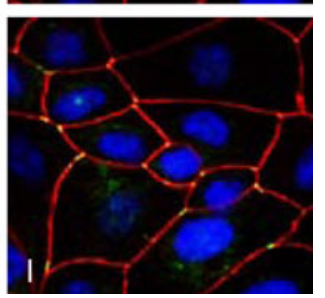


Fig. 5 a, b Confocal laser scanning microscopic images of tricellulin in HPAC cells at $4 \mathrm{~h}$ after $\mathrm{Ca}^{2+}$ repletion. Bar $20 \mu \mathrm{m}$. c, d Immuno-transmission electron microscopic images of tricellulin in HPAC cells at $4 \mathrm{~h}$ after $\mathrm{Ca}^{2+}$ repletion ( $T$ tricellular contact, $S$ space, arrows immunogold particles directed against tricellulin). Bar $50 \mathrm{~nm}$
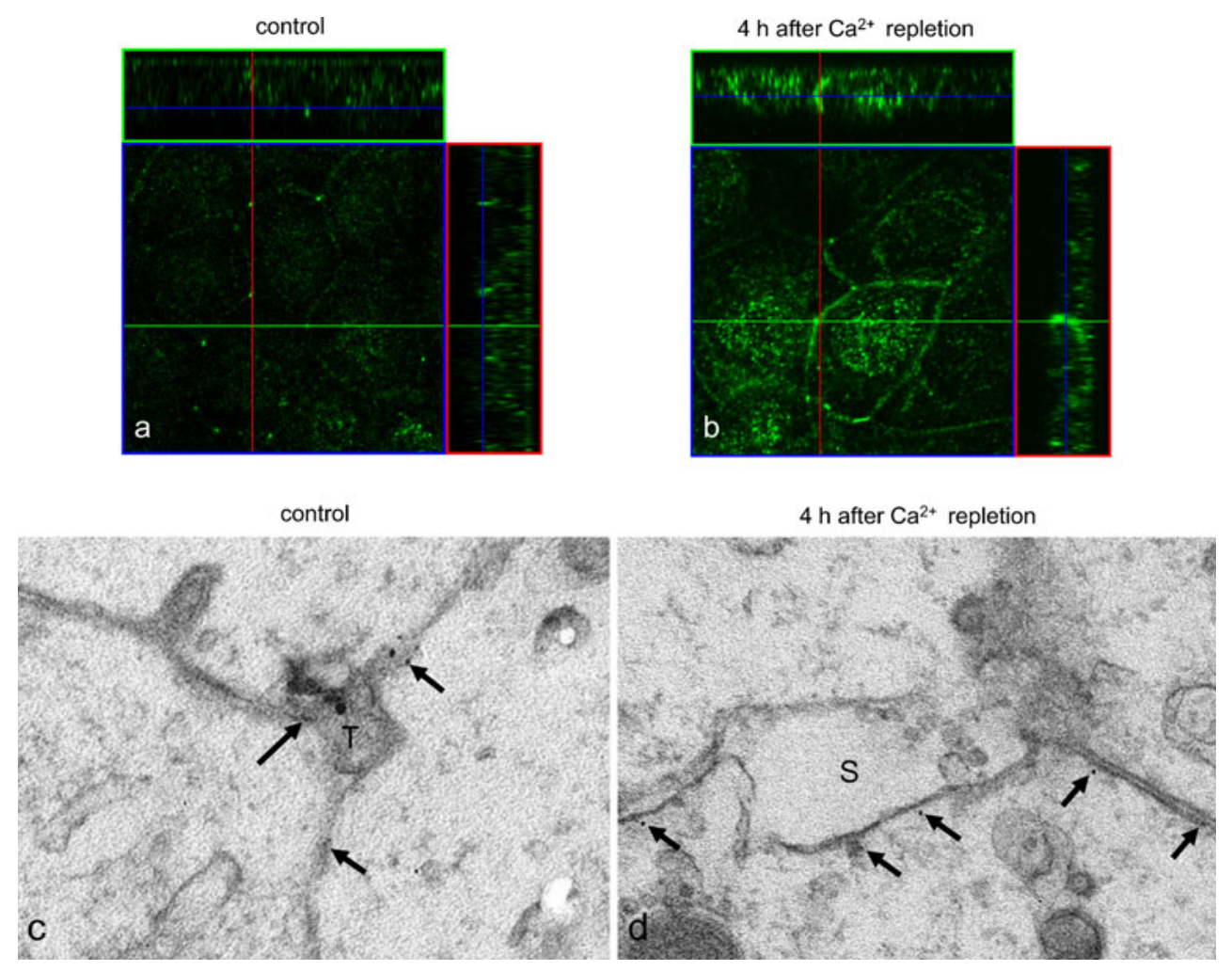

tricellulin during the process of the disruption and formation of tight junctions achieved by modulating extracellular $\mathrm{Ca}^{2+}$ conditions in the polarized human pancreatic cell line HPAC. Our results provide evidence showing that the dynamic changes of the distribution and phosphorylation of tricellulin in the course of the destruction and formation of tight junctions are probably linked to the barrier and fence functions of tight junctions.

$\mathrm{Ca}^{2+}$ depletion caused by EGTA treatment induced the disruption of tight junctions and displaced the tricellulin from tricellular contacts to bicellular junctions and finally to the cytoplasm; this was correlated with a significant reduction in TER (Figs. 1, 2). These alterations of tricellulin localization and TER were promptly reversed by the removal of EGTA. Under the same conditions, no significant change was observed in the localization of occludin. $\mathrm{Ca}^{2+}$ repletion after $\mathrm{Ca}^{2+}$ starvation induced tight junction formation and altered the localization of tricellulin from the cytoplasm to the basolateral membranes of bicellular junctions and finally to the apical sites of tricellular contacts (Fig. 4).

In the course of the $\mathrm{Ca}^{2+}$-dependent alterations of tricellulin localization, the band intensities and widths of tricellulin in Western blots transiently increased in both the whole lysate and the Triton-X-100-insoluble fraction without changes in its mRNA level (Figs. 1, 3; Supplemental Fig. 1). A possible cause for the increased intensity and width was the phosphorylation of the tricellulin protein, as previously described for occludin (Antonetti et al. 1999; Farshori and Kachar 1999; Andreeva et al. 2001). Consistently, when the intensity or width increased as a result of the upward band shift of tricellulin, protease-free alkaline phosphatase treatment reduced the band intensity or width, suggesting that the tricellulin was phosphorylated (Figs. 1, 3). Indeed, immunoprecipitation with the anti-tricellulin antibody confirmed that phosphothreonine considerably increased with the increasing band intensity of tricellulin in both the whole lysate and Triton-X-100-insoluble fraction (Figs. 1, 3), indicating that phosphorylated tricellulin was resistant to detergent extraction, similar to occludin (Sakakibara et al. 1997; Wong 1997). Tricellulin was transiently phosphorylated on threonine residue(s) when its localization changed, suggesting that phosphorylation might be closely associated with tricellulin displacement, i.e., internalization, during the disruption and formation of tight junctions. However, these results cannot completely exclude the possibility that EGTA treatment had inhibited the degradation of tricellulin and resulted in the increase of its band intensity, even though the band intensities of claudins and occludin were not altered under the same conditions.

The phosphorylation of tight junction proteins appears to play a central role in the regulation of tight junction assembly and function. The phosphorylation of occludin has been well examined in association with its localization and function (Sakakibara et al. 1997; Wong 1997; Seth et al. 2007; Murakami et al. 2009). As a result of experiments on confluent MDCK cells and $\mathrm{Ca}^{2+}$ repletion, the redistribution 
a
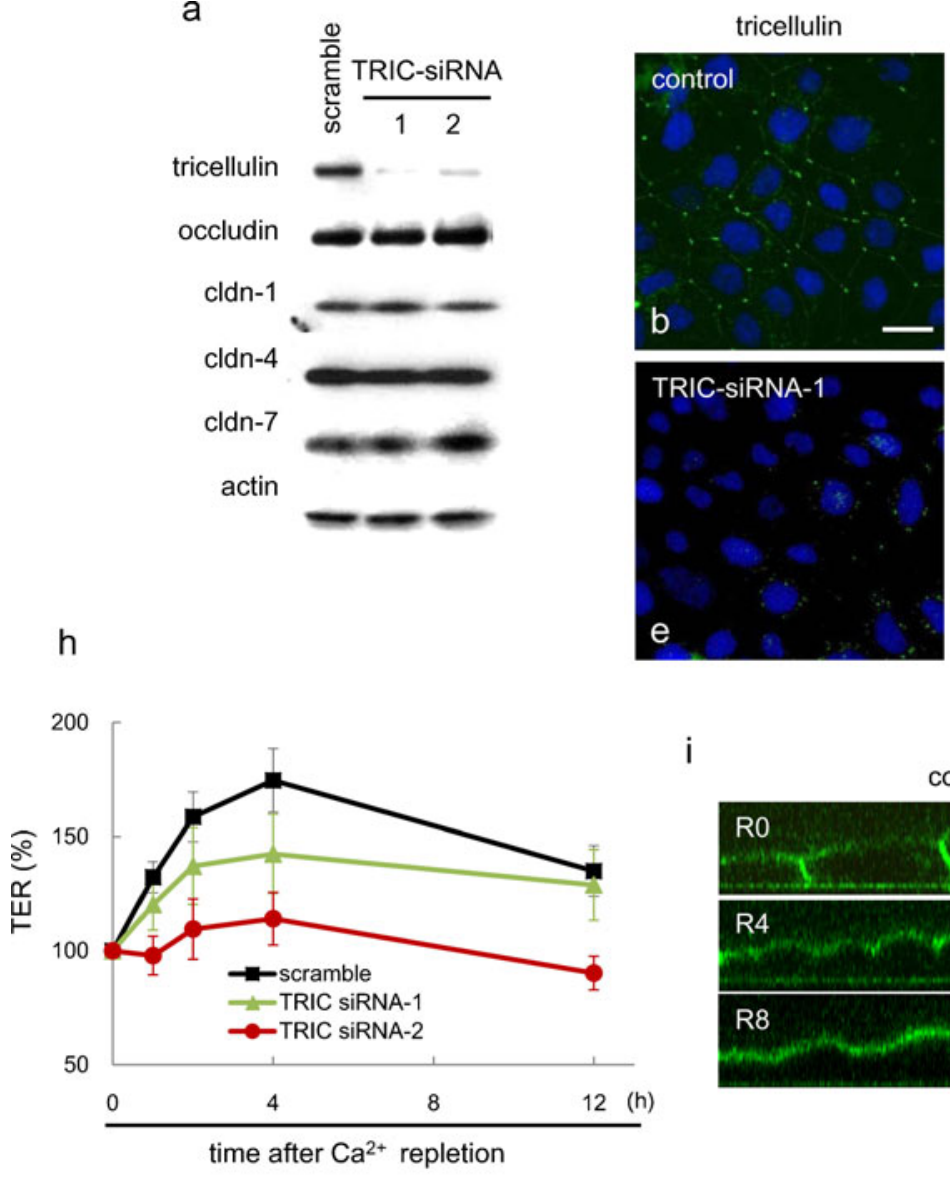
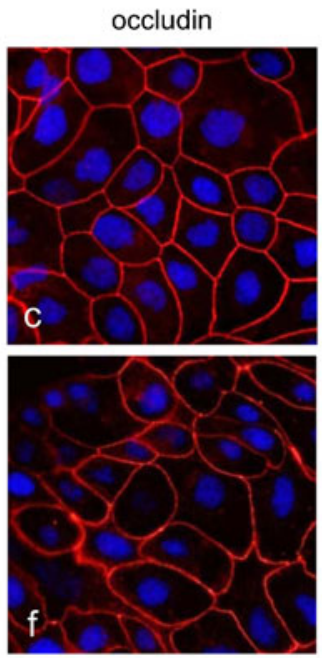
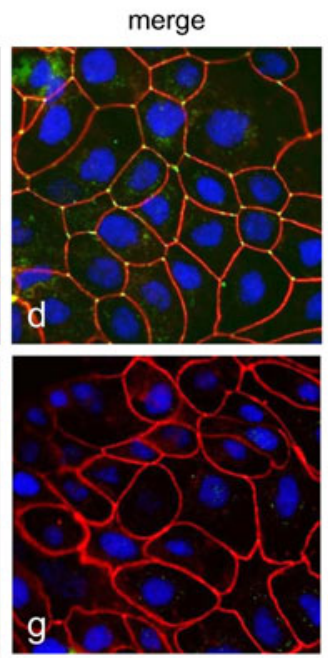

Fig. 6 Effects of small interfering RNA (siRNA) for tricellulin (TRIC) on the barrier and fence functions in HPAC cells after a $\mathrm{Ca}^{2+}$ repletion. a Western blotting for tricellulin, occludin and claudin (cldn) $-1,-4$, and -7 in whole cell lysates of HPAC cells treated with siRNAs for tricellulin and the negative scrambled control. b-g Immunostaining images obtained by using double-staining for tricellulin and occludin in HPAC

and phosphorylation of occludin during the opening and resealing of tight junctions has become well-known (Farshori and Kachar 1999). Like occludin, tricellulin appears to be phosphorylated (Ikenouchi et al. 2005). We have previously reported that threonine phosphorylation of tricellulin in HPAC cells is induced by treatment with the JNK activator anisomycin (Kojima et al. 2010). Whether these threonine residues are phosphorylated sequentially or randomly in each molecule or whether the phosphorylation of some residues is functionally more important than that of others remains elusive. The phosphorylation is sensitive to extracellular $\mathrm{Ca}^{2+}$ conditions, as for occludin but not for claudins (Farshori and Kachar 1999; Kubota et al. 1999). However, the specific kinases responsible for tricellulin phosphorylation are unclear, whereas occludin is phosphorylated by various kinases, including protein kinase C, protein kinase A, mitogen-activated protein kinases, phosphatidylinositol 3-kinase and the Ser/Thr kinases, namely casein kinase 1 and casein kinase 2 (Dörfel et al. 2009). cells treated with siRNA-1 for TRIC. Bar $20 \mu \mathrm{m}$. h TER values in HPAC cells pretreated with siRNAs for tricellulin after $\mathrm{Ca}^{2+}$ repletion. i Fence function as examined by diffusion of labeled BODIPYsphingomyelin through HPAC cell layer pretreated with siRNA for tricellulin before $\mathrm{Ca}^{2+}$ repletion ( $R$ recovery)

Since the C-terminus cytoplasmic sequence of tricellulin is highly similar to that of occludin, tricellulin might also bind to various kinases. Tricellulin is also thought to be present along the lateral membrane at tricellular tight junctions (Raleigh et al. 2010; Mariano et al. 2011). In the present study, at $4 \mathrm{~h}$ after $\mathrm{Ca}^{2+}$ repletion, tricellulin induced in the Triton-X-100-insoluble fraction and phosphorylated on threonine residues was localized not only at tricellular contacts but also in cytoplasm and at bicellular borders as shown by immunofluorescence microscopy and immuno-TEM analysis (Fig. 5). In Z-sections obtained by confocal laser microscopy, tricellulin was observed at the apical-most regions and basolateral membranes of tricellular contacts at $4 \mathrm{~h}$ after $\mathrm{Ca}^{2+}$ repletion (Fig. 5). The way in which tricellulin is trafficked to the tricellular contacts remains unclear, as is the manner in which the bicellular tight junction proteins occludin and claudins are trafficked to the tight junction regions. These results suggest that tricellulin is trafficked to the membranes of the bicellular borders and the basolateral 
membranes and then to the apical-most regions at the tricellular contacts during the formation of tight junctions. The phosphorylation of tricellulin might play an important role in these processes, as described above.

Although tricellulin expression is closely associated with the barrier function (Ikenouchi et al. 2005; Krug et al. 2009), the relationship between the phosphorylation of tricellulin and the barrier function is unclear. Furthermore, we do not know whether tricellulin affects the fence function. In the present study, when the dynamic changes of the distribution and phosphorylation of tricellulin were observed by using $\mathrm{Ca}^{2+}$ repletion, the knockdown of tricellulin by siRNAs delayed the recovery of both the barrier and fence functions after $\mathrm{Ca}^{2+}$ repletion (Fig. 6). These findings indicate that the expression of tricellulin might be closely associated with the barrier and fence functions during the formation of tight junctions.

In conclusion, the dynamic behavior of tricellulin, including phosphorylation, has been observed during the destruction and formation of tight junctions under various extracellular calcium conditions and is closely associated with both the barrier and fence functions of tight junctions. Tricellulin directly binds to marvelD3 and zonula occludens protein 1 (Riazuddin et al. 2006; Raleigh et al. 2010; Westphal et al. 2010) and forms homomeric complexes and heteromeric complexes with occludin (Westphal et al. 2010). More recently, Masuda and colleagues (2011) have reported that the cytoplasmic domain of LSR is responsible for the recruitment of tricellulin. The phosphorylation and dephosphorylation of tricellulin might play a role in its interaction with other tight junction proteins including LSR at tricellular tight junctions. Whether ubiquitylation is involved in the turnover and trafficking of tricellulin, as for occludin and claudins (Takahashi et al. 2009; Traweger et al. 2002), remains unclear. The mechanism and role of tricellulin phosphorylation need to be elucidated in future studies.

Open Access This article is distributed under the terms of the Creative Commons Attribution License that permits any use, distribution and reproduction in any medium, provided the original author(s) and the source are credited.

\section{References}

Andreeva AY, Kause E, Muller E-C, Blasig IE, Utepbergenov DI (2001) Protein kinase $C$ regulates the phosphorylation and cellular localization of occludin. J Biol Chem 276:38480-38486

Antonetti DA, Barber AJ, Hollinge LA, Wolpert EB, Gardner TW (1999) Vascular endothelial growth factor induces rapid phosphorylation of tight junction proteins occludin and zonula occluden 1. J Biol Chem 274:23463-23467
Balda MS, Whitney JA, Flores C, González S, Cereijido M, Matter K (1996) Functional dissociation of paracellular permeability and transepithelial electrical resistance and disruption of the apical-basolateral intramembrane diffusion barrier by expression of a mutant tight junction membrane protein. J Cell Biol 134:1031-1049

Cereijido M, Valdés J, Shoshani L, Contreras RG (1998) Role of tight junctions in establishing and maintaining cell polarity. Annu Rev Physiol 60:161-177

Dörfel MJ, Huber O (2012) Modulation of tight junction structure and function by kinases and phosphatases targeting occludin. J Biomed Biotechnol 2012:807356

Dörfel MJ, Westphal JK, Huber O (2009) Differential phosphorylation of occludin and tricellulin by CK2 and CK1. Ann N Y Acad Sci 1165:69-73

Farshori P, Kachar B (1999) Redistribution and phosphorylation of occludin during opening and resealing of tight junctions in cultured epithelial cells. J Membr Biol 170:147-156

González-Mariscal L, Tapia R, Chamorro D (2008) Crosstalk of tight junction components with signaling pathways. Biochim Biophys Acta 1778:729-756

Gumbiner BM (1993) Breaking through the tight junction barrier. J Cell Biol 123:1631-1633

Ikenouchi J, Furuse M, Furuse K, Sasaki H, Tsukita S, Tsukita S (2005) Tricellulin constitutes a novel barrier at tricellular contacts of epithelial cells. J Cell Biol 171:939-945

Ikenouchi J, Sasaki H, Tsukita S, Furuse M, Tsukita S (2008) Loss of occludin affects tricellular localization of tricellulin. Mol Biol Cell 19:4687-4693

Kojima T, Takano K, Yamamoto T, Murata M, Son S, Imamura M, Yamaguchi H, Osanai M, Chiba H, Himi T, Sawada N (2008) Transforming growth factor-beta induces epithelial to mesenchymal transition by down-regulation of claudin- 1 expression and the fence function in adult rat hepatocytes.Liver Int 28:534-545

Kojima T, Murata M, Yamamoto T, Lan M, Imamura M, Son S, Takano K, Yamaguchi H, Ito T, Tanaka S, Chiba H, Hirata K, Sawada N (2009) Tight junction proteins and signal transduction pathways in hepatocytes. Histol Histopathol 24:1463-1472

Kojima T, Fuchimoto J, Yamaguchi H, Ito T, Takasawa A, Ninomiya T, Kikuchi S, Ogasawara N, Ohkuni T, Masaki T, Hirata K, Himi T, Sawada N (2010) c-Jun N-terminal kinase is largely involved in the regulation of tricellular tight junctions via tricellulin in human pancreatic duct epithelial cells. J Cell Physiol 225:720-733

Korompay A, Borka K, Lotz G, Somorácz A, Törzsök P, Erdélyi-Belle B, Kenessey I, Baranyai Z, Zsoldos F, Kupcsulik P, Bodoky G, Schaff Z, Kiss A (2012) Tricellulin expression in normal and neoplastic human pancreas. Histopathology 60:E76-E86

Krug SM, Amasheh S, Richter JF, Milatz S, Günzel D, Westphal JK, Huber O, Schulzke JD, Fromm M (2009) Tricellulin forms a barrier to macromolecules in tricellular tight junctions without affecting ion permeability. Mol Biol Cell 20:3713-3724

Kubota K, Furuse M, Sasaki H, Sonoda N, Fujita K, Nagafuchi A, Tsukita $\mathrm{S}$ (1999) $\mathrm{Ca}^{2+}$-independent cell-adhesion activity of claudins, a family of integral membrane proteins localized at tight junctions. Curr Biol 9:1035-1038

Mariano C, Silva SL, Pereira P, Fernandes A, Brites D, Brito MA (2011) Evidence of tricellulin expression by immune cells, particularly microglia. Biochem Biophys Res Commun 409:799-802

Masuda R, Semba S, Mizuuchi E, Yanagihara K, Yokozaki H (2010) Negative regulation of the tight junction protein tricellulin by Snail-induced epithelial-mesenchymal transition in gastric carcinoma cells. Pathobiology 77:106-113

Masuda S, Oda Y, Sasaki H, Ikenouchi J, Higashi T, Akashi M, Nishi E, Furuse M (2011) LSR defines cell corners for tricellular tight junction formation in epithelial cells. J Cell Sci 124:548-555 
Murakami T, Felinski EA, Antonetti DA (2009) Occludin phosphorylation and ubiquitination regulate tight junction trafficking and vascular endothelial growth factor-induced permeability. J Biol Chem 284:21036-21046

Nusrat A, Parkos CA, Verkade P, Foley CS, Liang TW, InnisWhitehouse W, Eastburn KK, Madara JL (2000) Tight junctions are membrane microdomains. J Cell Sci 113:1771-1781

Ogasawara N, Kojima T, Go M, Fuchimoto J, Kamekura R, Koizumi J, Ohkuni T, Masaki T, Murata M, Tanaka S, Ichimiya S, Himi T, Sawada N (2009) Induction of JAM-A during differentiation of human THP-1 dendritic cells. Biochem Biophys Res Commun 389:543-549

Raleigh DR, Marchiando AM, Zhang Y, Shen L, Sasaki H, Wang Y, Long M, Turner JR (2010) Tight junction-associated MARVEL proteins marvelD3, tricellulin, and occludin have distinct but overlapping functions. Mol Biol Cell 21:1200-1213

Riazuddin S, Ahmed ZM, Fanning AS, Lagziel A, Kitajiri S, Ramzan K, Khan SN, Chattaraj P, Friedman PL, Anderson JM, Belyantseva IA, Forge A, Riazuddin S, Friedman TB (2006) Tricellulin is a tight-junction protein necessary for hearing. Am J Hum Genet 79:1040-1051

Sakakibara A, Furuse M, Saitou M, Ando-Akatsuka Y, Tsukita S (1997) Possible involvement of phosphorylation of occludin in tight junction formation. J Cell Biol 137:1393-1401

Sánchez-Pulido L, Martín-Belmonte F, Valencia A, Alonso MA (2002) MARVEL: a conserved domain involved in membrane apposition events. Trends Biochem Sci 27:599-601

Sawada N, Murata M, Kikuchi K, Osanai M, Tobioka H, Kojima T, Chiba H (2003) Tight junctions and human diseases. Med Electron Microse 36:147-156

Schneeberger EE, Lynch RD (1992) Structure, function, and regulation of cellular tight junctions. Am J Physiol 262:L647-L661

Schneeberger EE, Lynch RD (2004) The tight junction: a multifunctional complex. Am J Physiol Cell Physiol 286:C1213C1228
Seth A, Sheth P, Elias BC, Rao R (2007) Protein phosphatases 2A and 1 interact with occludin and negatively regulate the assembly of tight junctions in the CACO-2 cell monolayer. J Biol Chem 282:11487-11498

Takahashi S, Iwamoto N, Sasaki H, Ohashi M, Oda Y, Tsukita S, Furuse M (2009) The E3 ubiquitin ligase LNX1p80 promotes the removal of claudins from tight junctions in MDCK cells. J Cell Sci 122:985-994

Traweger A, Fang D, Liu YC, Stelzhammer W, Krizbai IA, Fresser F, Bauer HC, Bauer H (2002) The tight junction-specific protein occludin is a functional target of the E3 ubiquitin-protein ligase itch. J Biol Chem 277:10201-10208

Tsukita S, Furuse M, Itoh M (2001) Multifunctional strands in tight junctions. Nat Rev Mol Cell Biol 2:285-293

van Meer G, Simons K (1986) The function of tight junctions in maintaining differences in lipid composition between the apical and the basolateral cell surface domains of MDCK cells. EMBO J 5:1455-1464

Westphal JK, Dörfel MJ, Krug SM, Cording JD, Piontek J, Blasig IE, Tauber R, Fromm M, Huber O (2010) Tricellulin forms homomeric and heteromeric tight junctional complexes. Cell Mol Life Sci 67:2057-2068

Wong V (1997) Phosphorylation of occludin correlates with occludin localization and function at the tight junction. Am J Physiol 273: C1859-C1867

Yamaguchi H, Kojima T, Ito T, Kimura Y, Imamura M, Son S, Koizumi J, Murata M, Nagayama M, Nobuoka T, Tanaka S, Hirata K, Sawada N (2010) Transcriptional control of tight junction proteins via a protein kinase $\mathrm{C}$ signal pathway in human telomerase reverse transcriptase-transfected human pancreatic duct epithelial cells. Am J Pathol 177:698-712

Yen FT, Masson M, Clossais-Besnard N, André P, Grosset JM, Bougueleret L, Dumas JB, Guerassimenko O, Bihain BE (1999) Molecular cloning of a lipolysis-stimulated remnant receptor expressed in the liver. J Biol Chem 274:13390-13398 